\title{
Subjective Vitality Mediates the Relationship between Respect toward Partner and Subjective Happiness on Teachers
}

\author{
Erol Uğur ${ }^{1, *}$, Çınar Kaya ${ }^{2}$, Basri Özçelik ${ }^{1}$ \\ ${ }^{1}$ Department of Educational Sciences, Sakarya University, Turkey \\ ${ }^{2}$ Department of Educational Sciences, Bartın University, Turkey
}

Copyright $\bigcirc 2019$ by authors, all rights reserved. Authors agree that this article remains permanently open access under the terms of the Creative Commons Attribution License 4.0 International License

\begin{abstract}
Respect, subjective vitality, and subjective happiness can be associated with positive psychological functioning. In this study, subjective vitality was examined as a mediator on the relationship between respect toward partner and subjective happiness on a teachers' sample. The study is a quantitative cross-sectional mediation study. The data were collected from 172 married teachers by a questionnaire package that included the Respect toward Partner Scale, the Subjective Vitality Scale, and the Subjective Happiness Scale. Findings show that subjective happiness is predicted positively by respect toward partner and subjective vitality. Subjective vitality is predicted positively by respect toward partner. Also, the relationship between respect toward partner and subjective happiness is partially mediated by subjective vitality. Understanding the role of respect within close relationships could facilitate the development of interventions to enhance communication between partners about safety attitudes and decrease partner violence. Implications and limitations have been discussed within the scope of the relevant literature.
\end{abstract}

Keywords Subjective Vitality, Respect toward Partner, Subjective Happiness, Mediation Model

\section{Introduction}

Establishing close relationships is one of the core needs and is also a developmental task of human beings. Close relationships require respect, dedication, and caring as "ingredients" of a healthy life [1]. Partners getting respect from each other feel worthy, and experience higher levels of happiness in relationships [2]. Respectful romantic relationships have notable impacts on quality of life, psychological, and physical well-being [3]. A wide variety of studies on the importance of respect; concentrated on both direct and indirect predictors of respect [4], kindness [5], contemporary sexism and discrimination [6], conceptualization of respect [7], preventing gender-based violence [8], value education [9, 10, 11], respectful relationships program [12].

Respect is a multidimensional construct, and has substantial linkages with some of the psychological variables. Research indicates that higher levels of respect are positively linked with liking, loving, relationship satisfaction [4], self-esteem [13], and the quality of close relationship [14]. Negatively linked with lower levels of negative social behavior [15], attachment anxiety [4], disrespectful behaviors dating violence [16]; and bullying [17], Although a plethora of studies has been conducted about cognitive, emotional, and behavioral features of romantic relationships [4, 2], subjective vitality and subjective happiness were not examined with this respect, to our knowledge. Respect, subjective vitality and subjective happiness all seem to be related to positive psychological functioning. In this work, we aimed to examine a possible mechanism may be that it explains the relationship between respect toward partner and subjective happiness.

Respect is a pro-social behavior (e.g., emotional support, demonstrating trustworthiness and loyalty), and an essential part of successful and satisfying close relationship. Showing respect is defined as being supportive, trustworthy, reliable, caring, and behaving each other with equality and humility $[18,4,19]$. Respect in partnerships emphasizes dignity, equality, autonomy, protection of self, reciprocity, and is agreement on meeting a set of mutual expectations [20]. Therefore, respect may take the edge off misunderstandings between partners. The number of respectful attitudes that partners felt from each other improve their psychological well-being and their feelings acceptance. Respect is a way to reduce aggression because partners who feel respected are able to produce alternatives 
to aggression and violence [21].

Respect can be regarded as a facilitator for happiness and well-being in close relationships. Respect in close relationships promotes intimacy and enhances loyalty between partners. Respectful romantic relationships satisfy partners' certain developmental needs and have considerable impacts on quality of individuals' daily life, psychological and physical well-being [3]. The significant link between respect and self-esteem, dating violence, bullying, liking, relationship satisfaction, psychological well-being has been revealed by many studies [22]. In this regard, subjective vitality and subjective happiness may be two of the adaptive psychological constructs which may interact with respect toward partner.

Subjective vitality is one of the components of psychological functioning [22]. Subjective vitality was defined as "one's conscious experience of possessing energy and aliveness" (p. 530) by [23]. Subjective vitality is also a psychological energy, and being psychologically energized facilitates values directed actions and productivity. Being psychologically energized has been shown to be linked with greater positive affect, more resilience, and better overall psychological health and functioning $[24,22]$. Similarly, low vitality has been associated with impaired energy, and may be one of the indicators of underlying psychiatric problems such as depression [25, 26], and also it has been found that subjective vitality mediated the relationship between harmonious passion and work performance [27].

Subjective vitality is characterized by the state of feeling lively, alert, and being energetic [28]. Individuals who experience a high level of subjective vitality, have higher levels of motivation to conduct purposeful activities, cope with stressful events, and express greater psychological wellness. Research reveals that subjective vitality has positive linkages with life satisfaction, positive affectivity, self-esteem and psychological well-being [24, 29], mindfulness [30]. Subjective vitality is also predicted by psychological well-being, life skills, and life satisfaction [31].

Subjective happiness is another major indicator of well-being. Subjective happiness is considered as a facilitator for mental health and good coping skills [32]; a broad and comprehensive indicator of subjective well-being [33]. Individuals who report high levels of well-being seem to be able to sustain a high level of subjective happiness even during negative life settings. Subjective happiness may also lead to a more positive evaluation of life and a higher quality of life [34]. According to the related literature, subjective happiness is positively related to openness to experience [33], self-perceptions of well-being [35], positive self-evaluation in young [36], mental health [37], life satisfaction [38], satisfying relationships [39]. Besides subjective happiness is related negatively to the hopelessness, suicide risk, depressive symptoms, cognitive vulnerabilities [40; 32], fewer self-reported dry eye symptoms [34], and neuroticism [33].

\section{The Present Study}

Respect, subjective vitality and subjective happiness all seem to be related to positive psychological functioning. Respect in close relationships consists of dignity, honesty, empowerment, caring, self-esteem, productive communication [19]. Respectful relationships also enhance personal growth and sense of self-confidence; promote healthy self-expression; enable to feel acceptance and safety [41]. On account of this, there may be an association with respect toward partner and well-being indicators such as subjective happiness and subjective vitality. Thus, the present study examines the relationship of respect toward partner with subjective happiness via subjective vitality. Subjective vitality may be one of the variables, which mediate the relationship between respect toward partner and subjective happiness when the previous literature has been considered. Although there is overlapping between subjective happiness and subjective vitality, as components of well-being; the two of them belong to different theoretical frameworks and has different behavioral manifestations. Subjective happiness is a component of hedonic well-being; whereas the latter is a component of the eudaimonic well-being and is a better predictor of physical health [24].

Subjective vitality is a valuable personal strength to cope with stress effectively because if individuals feel that they do not have enough resources to handle the distress they may feel themselves less happy. Since human beings need social interactions as a mean of sharing their emotional experiences, in order to enhance their emotional strength and maintain their psychological and mental health, a respectful close relationship provides support, and it can be a facilitator for happiness [41, 42]. Additionally, individuals who have higher levels of subjective vitality are more energized psychologically and the state of being energized is linked with greater positive affect, more resilience, and better overall psychological health and functioning [22]. On the other hand, higher levels of respect improve individuals' perception of psychological well-being similar to subjective vitality and enhance sense of acceptance [21], and well-being is constructed based on the perspective of happiness [43].

Respectful close relationships are characterized by feelings honesty, care, trust and the increased sense of subjective happiness. Respect has a negative link with dating violence [16], and thus there may be an association between low levels of unkind attitudes and subjective happiness. Respect toward partner may also influence partner's psychological state [44], and partner who feels respected may experience positive feelings. Subjective vitality and subjective happiness are facilitators for mental health, effective coping skills, and subjective well-being 
$[33,32]$, they may be flourished in the atmosphere of respect. Finally, subjective vitality and subjective happiness are both related to central concept well-being, and thus there may be a significant link among them. And respect can be asserted to have an activating or nurturing role in cultivating a relationship which enables experiences of vitality and happiness. Subjective vitality may be a key process underlying the relationships between respect toward partner and subjective happiness since it has eudaimonic qualities. More specifically, in this study, we consider the relationship of three variables as the following: Respect is a prosocial behavior, which is associated with both eudaimonic and hedonic well-being. A possible mechanism may be that it activates the eudaimonic processes which end up in the experience of subjective vitality, and the interplay of these eudaimonic processes may be associated with higher levels of subjective well-being; which is envisioned as a hedonic outcome. In this model, we acknowledge the fact that respect behaviors may directly be associated with hedonic well-being directly. Taking the extensive influences and concomitants into consideration, it may be proposed that higher levels of subjective vitality may be linked to higher level of respect toward partner and subjective happiness. In relation to aim of the study, the following hypotheses have been suggested:

Hypothesis 1: Respect toward partner is positively related with subjective vitality.

Hypothesis 2: Respect toward partner is positively related with subjective happiness.

Hypothesis 3: Subjective vitality is positively related with subjective happiness.

Hypothesis 4: Subjective vitality mediates the relationship between respect toward partner and subjective happiness.

\section{Method}

\section{Participants}

Participants were 172 married teachers (114 women). Their ages ranged from 23 to 53 years old $(\mathrm{M}=33.6, \mathrm{SD}=$ 6.8). All of the participants voluntarily participated in the study. Convenience sampling was utilized. All the participants were working have been working in state schools.

\section{Instruments}

Respect toward Partner Scale. Respect was measured using the Respect toward Partner Scale [19]. Turkish adaptation of this scale was conducted by [45] The Respect toward Partner Scale is a 6-item (e.g., "I communicate well with my partner", "I honor my partner") self-report scale and each item were rated on a 5-point. There was no reverse coded item and all answers given would be totaled to indicate the level of respect toward partner. Higher scores indicated higher levels of respect in close relationship.

Subjective Vitality Scale. Subjective Vitality Scale [24] was used to measure the level of the subjective vitality. Subjective Vitality Scale measures vitality and consist of seven items (e.g., "In general, I feel alive and vital"). Responses were made on a 7-point scale from 1 (not at all true) to 7 (very true). Turkish adaptation of this scale was conducted by [46].

Subjective Happiness Scale. The Subjective Happiness Scale [47] was used to measure the subjective happiness level. The adaptation study of this scale into Turkish was conducted by [48]. The Subjective Happiness Scale is a 4-item (e.g., "Some people are generally very happy. They enjoy life regardless of what is going on, getting the most out of everything. To what extent does this characterization describe you?") self-report scale and each item was rated on a 7-point scale.

\section{Procedure \& Data Analysis}

Firstly, participants were informed of the purpose and of the voluntary nature of study and were ensured anonymity for all responses given. The measures were counterbalanced in administration. In order to determine the relationships among respect toward partner, subjective vitality, and subjective happiness; the Pearson correlation coefficient and regression analyses were used. In order to test whether subjective vitality mediated the link between respect toward partner and subjective happiness with regression analyses, Baron and Kenny's [49] recommendations were followed. These analyses were carried out via SPSS 20.0 and PROCESS macro [50].

\section{Results}

\section{Descriptive Data and Inter-correlations}

Table 1 shows the means, descriptive statistics, inter-correlations, and internal consistency coefficients of the variables used. According to the Table 1, there are significant correlations between respect toward partner, subjective vitality, and subjective happiness. Respect toward partner related positively to subjective vitality $(r=.29)$ and subjective happiness $(r=.28)$. Subjective vitality was also found to be positively $(r=.60)$ related to subjective happiness.

There were no significant differences in means of respect toward partner, subjective vitality, and subjective happiness, between males and females $(p>.05)$. There were no significant correlations between age and subjective vitality $(r=.06, p>.05)$ and subjective happiness, $(r=.07, p>.05)$. There was a significant negative correlation between age and respect toward 
partner $(r=-.16, p<.05)$.

Table 1. Descriptive Statistics and Inter-correlations of the Variables

\begin{tabular}{lcccc}
\hline \multicolumn{1}{c}{ Variables } & $\mathbf{1}$ & $\mathbf{2}$ & $\mathbf{3}$ & $\mathbf{4}$ \\
\hline 1. Subjective vitality & 1.00 & & & \\
\hline 2. Respect toward partner & $.29^{* *}$ & 1.00 & & \\
\hline 3. Subjective happiness & $.60^{* *}$ & $.28^{* *}$ & 1.00 & \\
\hline 4. Age & .06 & $-.16^{*}$ & .07 & 1.00 \\
\hline Mean & 34,83 & 26,09 & 20,16 & 33,58 \\
\hline Standard deviation & 8,12 & 3,80 & 3,89 & 6,825 \\
\hline Cronbach's $\alpha$ & .85 & .87 & .69 & $\mathrm{NA}$ \\
\hline${ }^{*} \mathrm{p}<.05^{* *} \mathrm{p}<.01$ & & & & \\
\hline
\end{tabular}

\section{Examining the Mediating Role of Subjective Vitality}

Firstly it was verified that respect toward partner and subjective vitality were positively related $(\beta=.29, t=4.018$, $\left.\mathrm{df}=169, p<.001,95 \% C I=.32, .95, R^{2}=.09\right)$. Then it was found that there was positive relationship between subjective vitality and subjective happiness $(\beta=.60, t=$ 9.741, $\left.d f=169, p<.001,95 \% C I=.22, .35, R^{2}=.36\right)$. To examine the last steps of mediation procedure, hierarchical regression analysis was performed. The results of the analysis demonstrated that respect toward partner was positively related with subjective happiness $(\beta=.28, t=$ 3.736, $\left.\mathrm{df}=169, p<.001,95 \% C I=.13, .44, R^{2}=.08\right)$.
However, when subjective vitality and respect toward partner were taken together in the regression analysis, the significance of the relationship between respect toward partner and subjective happiness $(\beta=.11, t=1.699, \mathrm{df}=$ $168, p<.001,95 \% C I=-.01, .26, R^{2}=.37$ ) decreased, yet the relationship between respect toward partner and subjective happiness was significant. According to [49], findings indicated a partial mediation. The results are presented in Figure 1.

Bootstrapped confidence intervals and of coefficients of indirect effects were calculated using PROCESS Macro [50] for testing the statistical significance and magnitudes of the partial mediational effect of subjective vitality in the relationship between respect toward partner and subjective happiness. The indirect effect coefficient was .096 $(\mathrm{SE}=.03)$ was significantly different from zero in a $95 \%$ bias-corrected bootstrap confidence interval and ranged from .043 (BootLLCI) to .16 (BootULCI). Preacher and Kelley's (2011) Kappa squared indirect effect coefficient was $.13(\mathrm{SE}=.04)$ ranging from .062 (BootLLCI) to .213 (BootULCI). All the confidence intervals excluded the point of zero and the Normal theory based Sobel Z test [51] also revealed that the partial mediation effect was statistically significant $(Z=2,9661, p<.01)$. Therefore, based on these results it can be claimed that subjective vitality partially explains the relationship between respect toward partner and subjective happiness.

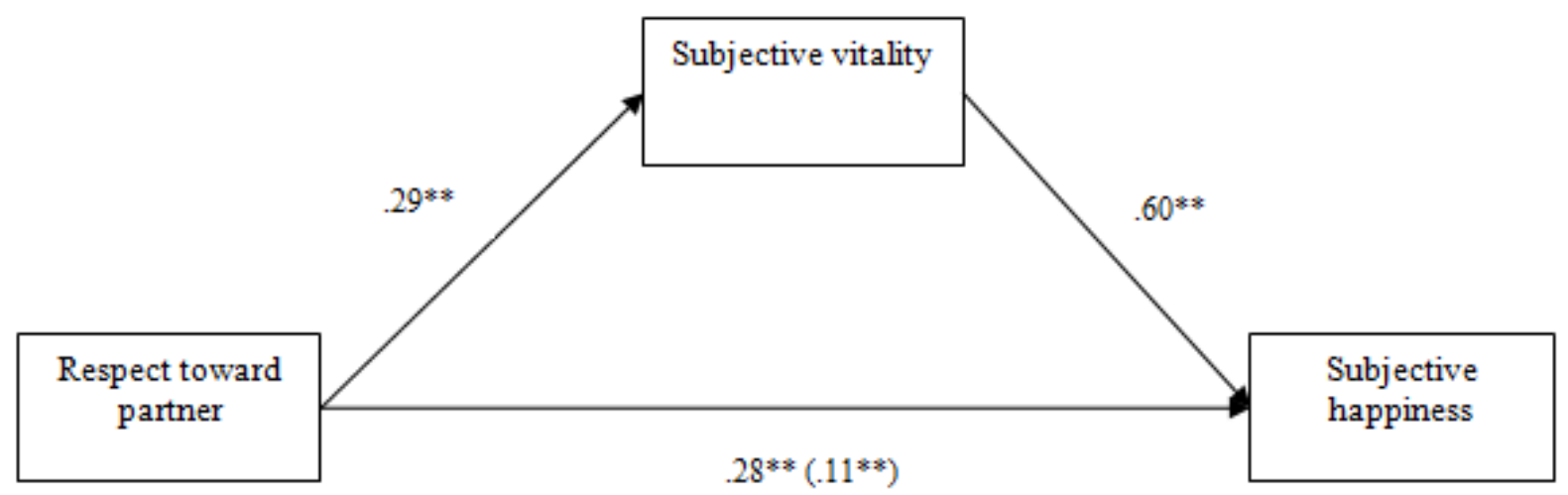

$* * \mathrm{p}<.01$

Figure 1. Standardized regression coefficients for the relationship between respect toward partner and subjective happiness as mediated by subjective vitality. The standardized regression coefficient between respect toward partner and subjective happiness, controlling for subjective vitality, is in parentheses. 


\section{Discussion}

The purpose of the present study was to investigate subjective vitality as a mediator on the relationship between respect toward partner and subjective happiness. This is a preliminary work for understanding the roles of subjective vitality and subjective happiness and how respectful toward partner may be a possible contributor for well-being. As predicted, findings revealed that the relationship between respect toward partner and subjective happiness was partially mediated by subjective vitality. Firstly, respect toward partner was related positively to subjective vitality. As mentioned in the previous studies it was revealed that respect has remarkable impacts on quality of individuals' daily life, psychological and physical well-being [3]. People who receive respect, may quite likely feel positively and as mentioned before a respectful close relationship can be a great way for happiness and being energized [41] and energized people has more potential to cope with their problems and have more optimistic thoughts about their power to change their life [22]. Clearly, concepts of respect toward partner and subjective vitality have similar aspects and both of them are related to well-being. Respect toward partner may play a trigger role to gain and enhance subjective vitality because all requirements of respect such as being supportive, trustworthy, reliable, caring, and treating each other with equality and humility [18] commitment, intimacy, passion, love and honesty [52] have very close contact with the component of subjective vitality.

Secondly, respect toward partner was found associated positively with subjective happiness, indicating that to be respected and cared about is associated with feeling oneself happy. Also the increased sense of subjective happiness is shaped by feelings of warmth, connectedness, and contentment [53]. Moreover, when people get respect from partner or others, they feel positive, understood and comfortable that contributes to having more feelings of subjective happiness by inhibiting unkind manners [41].

Thirdly, as anticipated, subjective vitality predicted subjective happiness in a positive way. Because subjective happiness is considered a broad indicator of subjective well-being and related to mental health [43, 37 ] life satisfaction [38] positive emotions [39], and self-enhancing bias [54]. Similarly, subjective vitality related to a plethora of adaptive components such as life satisfaction, self-actualization, conscientiousness, positive affectivity, self-esteem, extraversion, mindfulness and intrinsic motivation $[30,55,24]$. In accord with the findings, it can be stated that positive effect of subjective vitality on subjective happiness seems very conceivable, and individuals felt more vitality may rise their feelings of subjective happiness.

In addition, findings of the present study have proved that subjective vitality partially mediated the relationship between respect toward partner and subjective happiness. Findings extend what is known about respect toward partner and its relation with subjective vitality. What is identified as respect and its core components, how respect is expressed, and how people especially partners show respect behaviors are functional research questions to take into consideration. Understanding the role of respect within close relationships could facilitate the development of interventions to enhance communication between partners about safety attitudes and decrease partner violence [18]. In a disrespectful relationship, partners feel that unsafe, depressed and unhappy [41]. There is also a significant negative linkage between depressive symptoms and subjective vitality; and a positive association between feelings of safeness and subjective happiness [56].

Although it has been mentioned that respect linked to emotional, physical well-being and psychological health, no research has addressed factors that might mediate these relationships. In other words, literature is limited about in which direction a pro-social variable relates with subjective vitality. The results of the present study are particularly remarkable because it suggested that respect as a pro-social behavior [18], associated with subjective happiness through subjective vitality. The current findings may contribute to people's understanding of the relationships among subjective vitality, respect toward partner and subjective happiness. The findings may also be useful in integrating knowledge about respect toward partner, subjective happiness and subjective vitality into a preventative circle. It may be functional to examine relations between respect and known core skills, such as psychological well-being, decision-making, self-regulation, self-efficacy.

Limitations of the present study should be acknowledged when evaluating the findings. The data reported in the study for respect toward partner, subjective vitality, and subjective happiness is cross sectional. Hence, no definitive statements can be made about causality. All in all, this study shows that partners who have a higher level of respect are more likely to be high in subjective happiness and subjective vitality. Another limitation of the study was that the study group completely consisted of teachers working in state schools. Although forming the study group within the same vocational group has enabled controlling for the effects of many different variables such as socioeconomic status, and vocational variables; it limits the generalizability of the findings. Finally, further studies using a longitudinal design would provide a better understanding of directionality in the relation among respect in close relationships, subjective vitality, and subjective happiness. Further examination is also essential to comprehend the dynamics of respect in different relationship types and future studies may shed light on other structures such as marital adjustment, social self-efficacy, and the effect of the culture. It is clear that more research needs to be done to understand how social, emotional and psychological variables are associated to subjective vitality. 


\section{REFERENCES}

[1] Eryılmaz, A., \& Ercan, L. (2010). Beliren yetişkinlikte romantik yakınlığı başlatma: yakınlığa karşı yalıtılmışlık mı? Türk Psikolojik Danışma ve Rehberlik Dergisi, 4(34), 119-127.

[2] Markus, H. R. (2004). A social psychological model of behavior. Dialogue, 19(1), 1-4.

[3] Huo, Y. J., \& Binning, K. R. (2008). Why the psychological experience of respect matters in group life: An integrative account. Social \& Personality Psychology Compass, 2, 1570-1585.

[4] Frei, J. R., \& Shaver, P. R. (2002). Respect in close relationships: Prototype definition, self-report assessment, and initial correlates. Personal Relationships, 9, 121-139.

[5] Peterson, C., \& Seligman, M., E., P. (2004). Character strengths and virtues: A handbook and classification. New York: Oxford University Press.

[6] Jackson, L. M., Esses, V. M., \& Burris, C. T. (2001). Contemporary sexism and discrimination: The importance of respect for men and women. Personality and Social Psychology Bulletin, 27(1), 48-61.

[7] Langdon, S. W. (2007). Conceptualizations of respect: Qualitative and quantitative evidence of four (Five) themes. The Journal of Psychology: Interdisciplinary and Applied, 141(5), 469-484.

[8] Ollis, D. (2014). The role of teachers in delivering education about respectful relationships: exploring teacher and student perspectives. Health Education Research, 29(4), 702-713.

[9] İşcan, C. D. (2011). Values education and some suggestions to teachers. Hacettepe University Joumal of Education, 40, $245-255$

[10] Balcı, F. A., \& Yelken, T. Y. (2013). İlköğretim sosyal bilgiler programında yer alan değerler ve değer eğitimi uygulamaları konusunda öğretmen görüşleri.Ahi Evran Üniversitesi Kırşehir Eğitim Fakültesi Dergisi (KEFAD), 14(1), 195-213.

[11] Taşdelen, V. (2015). Oral tradition and values education: A case study dede korkut stories. International Online Journal of Educational Sciences, 7(1), 219-229.

[12] Buote, D., \& Berglund, P. (2010). Promoting social justice through building healthy relationships: Evaluation of SWOVA's 'Respectful Relationships' program Education, Citizenship and Social Justice, 5(3), 207-220.

[13] Ellemers, N., Doosje, B., \& Spears, R. (2004). Sources of respect: The effects of being liked by ingroups and outgroups. European Journal of Social Psychology, 34, 155-172.

[14] Gizir, C. A. (2012). İlişki İnançları Ölçeği'nin Uyarlanması: Geçerlik ve güvenirlik çalışmaları. Mersin Üniversitesi Eğitim Fakültesi Dergisi, 8(2), 37-45.

[15] Clemans, K. H., Graber, J. A., \& Bettencourt, A. F. (2012). Adult-directed and peer-directed respect for authority: relationships with aggressive and manipulative behavior. Journal of Research on Adolescence, 22(3), 480-486.

[16] Martin, C. E., Houston, A. M., Mmari, K. N., \& Decker, M., R. (2012). Urban teens and young adults describe drama, disrespect, dating violence and help-seeking preferences. Maternal and Child Health Journal, 16, 957-966.

[17] Langdon, S. W., \& Preble, W. (2003, April). Qualitative and quantitative definitions and experiences of respect in adolescents. Poster session presented at Society for Research in Child Development conference, Tampa, FL.

[18] Gowen, L. K., Catania, J. A., Dolcini, M. M., \& Harper, G. W. (2014). The meaning of respect in romantic relationships among low-1ncome African American adolescents. Journal of Adolescent Research, 29(5), 639-662.

[19] Hendrick, S. S., \& Hendrick, C. (2006). Measuring respect in close relationships. Journal of Social and Personal Relationships, 23, 881-899.

[20] Goodman, J. F. (2009). Respect-due and respect-earned: Negotiating student-teacher relationships. Ethics and Education, 4(1), 3-17.

[21] Leary, J. D., Brennan, E. M., \& Briggs, H. E. (2005). The African-American adolescent respect scale: A measure of a prosocial attitude. Research on Social Work Practice, 15, $462-469$.

[22] Juhl, J., \& Routledge, C. (2015). The awareness of death reduces subjective vitality and self-regulatory energy for individuals with low interdependent self-construal. Motivation and Emotion, 1-10.

[23] Ryan, R. M., \& Deci, E. L. (2008). From ego depletion to vitality: Theory and findings concerning the facilitation of energy available to the self. Social and Personality Psychology Compass, 2, 702-717.

[24] Ryan, R. M., \& Frederick, C. (1997). On energy, personality and health: Subjective vitality as a dynamic reflection of well-being. Journal of Personality, 65, 529-565.

[25] Avlund, K. (2010). Fatigue in older adults: An early indicator of the aging process?. Aging Clinical and Experimental Research, 22(2), 100-115.

[26] Maynard, S., Keijzers, G., Hansen, Å. M., Osler, M., Molbo, D., Bendix, L., ... \& Bohr, V. A. (2015). Associations of subjective vitality with DNA damage, cardiovascular risk factors and physical performance. Acta Physiologica, 213(1), 156-170.

[27] Dubreuil, P., Forest, J., \& Courcy, F. (2014). From strengths use to work performance: The role of harmonious passion, subjective vitality, and concentration. The Journal of Positive Psychology, 9(4), 335-349.

[28] Moutão, J. M., Mendes Alves, S., \& Cid, L. (2013). Translation and validation of the subjective vitality scale in a portuguese sample of exercise participants. Revista Latinoamericana de Psicología, 45(2), 223-230.

[29] Ortigosa-Márquez, J. M., Carranque-Cháves, G. A., \& Hernández Mendo, A. (2015). Effects of autogenic training on lung capacity, competitive anxiety and subjective vitality. Biomedical Research, 26(1), 71-76.

[30] Visser, P. L., Hirsch, J. K., Brown, K. W., Ryan, R., \& 
Moynihan, J. A. (2014). Components of sleep quality as mediators of the relation between mindfulness and subjective vitality among older adults. Mindfulness, 1-9.

[31] Fini, A. A. S., Kavousian, J., Beigy, A., \& Emami, M. (2010). Subjective vitality and its anticipating variables on students. Procedia Social and Behavioral Sciences, 5, 150-156.

[32] Pompili, M., Innamorati, M., Lamis, D. A., Lester, D., Di Fiore, E., Giordano, G., ... \& Girardi, P. (2015). The interplay between suicide risk, cognitive vulnerability, subjective happiness and depression among students. Current Psychology, 1-16.

[33] Lauriola, M., \& Iani, L. (2015). Does positivity mediate the relation of extraversion and neuroticism with subjective happiness?. PloS One, 10(3), 1-16.

[34] Kawashima, M., Uchino, M., Yokoi, N., Uchino, Y., Dogru, M., Komuro, A., ... \& Tsubota, K. (2015). Associations between Subjective Happiness and Dry Eye Disease: A New Perspective from the Osaka Study. PloS one, 10(4), 1-11.

[35] Diener, E. (2000). Subjective well-being: The science of happiness and a proposal of a national index. American Psychologist, 55, 34-43.

[36] Cheng, H., \& Furnham, A. (2003). Personality, self- esteem, and demographic predictions of happiness and depression. Personality and Individual Differences, 34, 921-942.

[37] Liem, J .H., Lustig, K., \& Dillon, C. (2010) Depressive symptoms and life satisfaction among emerging adults: a comparison of high school dropouts and graduates. Journal of Adult Development, 17(1), 33-44.

[38] Garcia, D., \& Siddiqui, A. (2009). Adolescents' affective temperaments: Life satisfaction, interpretation and memory of events. The Journal of Positive Psychology, 4, 155-167.

[39] Diener, E., \& Seligman, M. E. P. (2002). Very happy people. Psychological Science, 13, 81-84.

[40] Chaplin, T. M. (2006). Anger, happiness, and sadness: Associations with depressive symptoms in late adolescence. Journal of Youth and Adolescence, 35, 977-986.

[41] Healey, J. (2012). Respectful relationships. Issues in society. Thirroul, N.S.W.: Spinney Press.

[42] Heaphy, E. D., \& Dutton, J. E. (2008). Positive social interactions and the human body a work: linking organizations and physiology. Academy of Management Review, 33, 137-162.

[43] Scott, K. (2015). Happiness on your doorstep: Disputing the boundaries of wellbeing and localism. The Geographical Journal, 181(2), 129-137.

[44] Deutsch, N. L., \& Jones, J. N. (2008). "Show me an ounce of respect": Respect and authority in adult-youth relationships in after-school programs. Journal of Adolescent Research, $23,667-688$

[45] Akın, A., Ugur, E., \& Özçelik, B. (2015). The Respect Toward Partner Scale: A validity and reliability study. The Journal of International Social Research, 8(41), 850-855.

[46] Akın, A., Satici, S. A., Arslan, S., Akın, Ü., \& Kayıs, A. R. (2012, February): The validity and the reliability of the Turkish version of the Subjective Vitality Scale. Paper presented at the $4^{\text {rd }}$ World Conference on Educational Sciences, February, 2-5, Barcelona, Spain.

[47] Lyubomirsky, S., \& Lepper, H. S. (1999). A measure of subjective happiness: Preliminary reliability and construct validation. Social Indicators Research, 46, 37-155.

[48] Akın, A., \& Satıcı, S. A. (2011). Subjective Happiness Scale: A study of validity and reliability. Sakarya University Journal of Education Faculty, 21, 65-77.

[49] Baron, R. M., \& Kenny, D. A. (1986). Moderator-mediator variables distinction in social psychological research: Conceptual, strategic, and statistical considerations. Journal of Personality and Social Psychology, 6, 1173-1182.

[50] Hayes, A. F. (2011). My macros and code for SPSS and SAS. Retrieved September, 27, 2011.

[51] Sobel, M. E. (1982). Asymptotic confidence intervals for indirect effects in structural equation models. In S. Leinhardt (Ed.), Sociological methodology (pp. 290-312). Washington DC: American Sociological Association.

[52] Fletcher, G. J. O., Simpson, J. A., \& Thomas, G. (2000). The measurement of perceived relationship quality components: A confirmatory factor analytic approach. Personality and Social Psychology Bulletin, 26, 340-354.

[53] Kelly, A. C., Zuroff, D. C., Leybman, M. J., \& Gilpert, P. (2012). Social safeness, received social support, and maladjustment: Testing a tripartite model of affect regulation. Cognitive Therapy and Research, 36(6), $815-826$.

[54] Lee, J. Y., \& Im, G. S. (2007). Self-enhancing bias in personality, subjective happiness, and perception of life events: A replication in a Korean aged sample. Aging and Mental Health, 11, 57-60.

[55] Balaguer, I., Castillo, I., Duda, J. L., \& García-Merita, M. (2011). Associations among perceived motivational climate created by the coach, dispositional orientation, motivational regulations and subjective vitality in young female tennis players. Revista de Psicología del Deporte, 20, 133-148.

[56] Niemiec, C. P., Lynch, M. F., Vansteenkiste M, et al. (2006). The antecedents and consequences of autonomous self-regulation for college: A self-determination theory perspective on socialization. Journal of Adolescence, 29, 761-775. 